\title{
Therapeutic Aspects of Mesenchymal Stem Cell-Based Cell Therapy with a Focus on Human Amniotic Epithelial Cells in Multiple Sclerosis: A Mechanistic Review
}

\author{
Reza ArefNezhad ${ }^{1}$, Hossein Motedayyen², Ali Mohammadi ${ }^{3}$ \\ ${ }^{I}$ Department of Anatomy, School of Medicine, Shiraz University of Medical Sciences, Shiraz, Iran \\ ${ }^{2}$ Autoimmune Diseases Research Center, Kashan University of Medical Sciences, Kashan, Iran \\ ${ }^{3}$ Cell Biology and Molecular-Genetics Department, Marand Azad University, Marand, Iran
}

Multiple sclerosis (MS) is an inflammatory disease of central nervous system (CNS). The mmune system plays an important role in its pathogenesis. Current treatments are unable to cure patients and prevent the progression of MS lesions. Stem cell-based cell therapy has opened a new window for MS treatment. Stem cells regulate immune responses and improve axonal remyelination. Stem cells can be obtained from different origins such as embryonic, neural, bone marrow, and adipose tissues. But yet there is a challenge for the selection of the best cell source for stem cell therapy. Mesenchymal stem cells (MSCs) are a type of stem cell obtained from different origins and have significant immunomodulatory effects on the immune system. The increasing evidence have suggested that umbilical cord and adipose tissue can be a suitable source for isolation of MSCs. Moreover, human amniotic epithelial cells (hAECs) as novel stem cell origins by having immunoregulatory effects, regenerative effects, and less capacity of antigenicity can be a candidate for MS treatment. This review discussed the mechanistic effects of MSCs with a focus on human amniotic epithelial cells, which can be used to treatment and improvement of outcome in MS disease.

Keywords: Multiple sclerosis, Human amniotic epithelial cell, Mesenchymal stem cell, Immunomodulatory effects, Regenerative impacts

\section{Introduction}

Neurodegenerative disorders are defined as chronic and

Received: February 17, 2021, Revised: April 4, 2021,

Accepted: April 13, 2021, Published online: June 30, 2021

Correspondence to Hossein Motedayyen

Autoimmune Diseases Research Center, Shahid Beheshti Hospital, Kashan University of Medical Sciences, 5th Kilometer of Ravand Road, Kashan 8717765761, Iran

Tel: +98-3155623015, Fax: +98-3155578011

E-mail: hmotedayyen@gmail.com

(a) This is an open-access article distributed under the terms of the Creative Commons Attribution Non-Commercial License (http://creativecommons.org/ licenses/by-nc/4.0/), which permits unrestricted non-commercial use, distribution, and reproduction in any medium, provided the original work is properly cited.

Copyright (c) 2021 by the Korean Society for Stem Cell Research progressive processes which result in the deposition of abnormal forms of specific proteins in the nervous system and destruction of neurons in motor, sensory, or cognitive systems (1). These disorders mainly occur in females and subjects with age range of 20 to 30 years (2). Besides, it is estimated that more than 2.5 million subjects have multiple sclerosis (MS) around the world which need to effective treatments to recover disability and improve the central nervous system (CNS) functions (2). The major obstacle of curative treatment of MS is an unsuccessful regeneration of neurons (3). The most common treatments for MS exert therapeutic impacts through inhibiting immune reactions $(2,4)$. However, the most of these therapeutic approaches are unable to stop the degeneration of nerve tissue in aggressive MS (5). Among these methods, stem cell based-cell therapies have a promising outlook for 
the remedy of neurological disorders by differentiation into astrocytes and oligodendrocytes effectively in vivo and in vitro as well as the secretions of neurotrophic agents which have immunoregulatory effects and regenerative roles for remyelination and thereby can decrease neural damages (6). There are some challenges for using stem cells as a curative approach in clinical trials because they can quickly proliferate and subsequently have a capacity for tumorigenicity (7). However, increasing evidence have shown that stem cell therapy can have positive effects on animal models with neurological diseases $(7,8)$. Clinical applications of adult stem cells, particularly mesenchymal stem cells (MSCs) and human amniotic epithelial cells (hAEC), have been recommended for the treatment of neurological disorders such as MS (9-11). These cells can easily be isolated, expanded, and manipulated ex vivo (12). They can effortlessly differentiate into mesodermal lineages (13). Other advantages of therapeutic applications of MSCs and hAECs include their capability to transport from blood to damaged sites, their relative safety, and low immunogenicity in comparison with other stem cell sources $(13,14)$. Hereby, the present review aimed to describe and discuss evidence regarding MSC-based therapies with concentrating on hAECs and their mechanisms for treating MS.

\section{MS and Its Pathogenesis}

Multiple sclerosis (MS) is a chronic and progressive neuro-inflammatory disease of the CNS, leading to axonal lack and myelin disruption. Among this, immune cells play a critical role in the pathogenesis of MS $(15,16)$. The immune system modulates neural evolution via regulating oligodendrogenesis, neurogenesis, and synaptic organization. In addition to environmental factors, genetic factors such as immune system regulating genes including major histocompatibility complex (MHC), T-cell receptor (TCR), immunoglobulin (Ig), and cytokines can increase the risk of MS $(2,17)$. Formations of sclerotic plaques and lesions in the CNS and the cerebrospinal cord are the features of MS. Common hypothesis indicates that when autoimmune cascade initiates, blood-brain barrier (BBB) disrupts and autoreactive $\mathrm{T}$ cells migrate to the CNS and then destroy myelin sheath and create lesions and plaques $(2,4)$. Disappearing of myelin sheath, which has a considerable role in survival and integration of axon, is a major reason for progression of MS although axon destruction occurs in primary phases of MS and remains permanent (3). T helper 1 (Th1) and T helper 17 (Th17) cells are the major effector cells that cause demyelination and destroy the
CNS $(15,16)$. However, $\mathrm{T}$ cells alone cannot form lesions and plaques and other immune cells play important roles in the pathogenesis of MS. Th1 and Th17 produce inerleukine-1 (IL-1), IL-17, tumor necrosis factor- alpha (TNF- $\alpha$ ), interferon-gamma (IFN- $\gamma$ ), and other pro-inflammatory cytokines (18). The consequence of macrophage activated by Thl cytokines is the destruction of the myelin and exposure of more CNS antigens. In vivo studies have shown that Thl cytokines such as IFN- $\gamma$, lymphotoxin (LT)- $\alpha$ and IL-2 have the important roles in the pathogenesis of MS. Furthermore, TNF- $\alpha$ is associated with progression of the disease. $\mathrm{CD} 8+\mathrm{T}$ cells are also observed in MS lesions, especially around the blood vessel. Clonal expansion of CD8 $+\mathrm{T}$ cell is more than CD4+ $\mathrm{T}$ cell and CD8 $+\mathrm{T}$ cell number is largely correlated to axons injury (1). Although it is shown that autoreactive $\mathrm{T}$ cells are the main effector cells responsible for the pathogenesis of disease, previous studies have reported that autoreactive B cells also participate in neural damages and their myelin sheaths and axons, through autoantibody productions, antigen presentations, and cytokine secretions (19). Clinical and experimental studies have shown that autoantibodies can be major components of the immune system that can be detected in MS plaques. In this notion, there are some studies showing the associations between immunoglobulin $\mathrm{G}$ (IgG) and MS signs. Moreover, it is indicated that $\mathrm{IgG}$, especially $\mathrm{IgG}$ against myelin basic proteins (MBP) and proteolipid proteins (PLP), can be considered as the hallmarks of MS. However, these antibodies have the unknown roles in its pathogenesis (Fig. 1) (20).

\section{Mesenchymal Stem Cells (MSCs)}

MSC can be isolated from all connective tissues including bone marrow, umbilical cord, adipose tissue, dental tissues, brain, and fetal lung (21-23). Several studies have shown that MSCs can differentiate into monocytes and neurons in vitro and in vivo (24). MSCs can migrate to areas of injured tissue via expressions of receptors for chemokines such as CCR1, CXCR4, CXCR5, and CXCR6, and some growth factors (6).

MSCs may support axon and increase neural stability through anti-oxidant and anti-apoptotic impacts and/or trophic factor secretions (25). MSCs can recruit oligodendrocyte precursors to the CNS and induce differentiation of these cells into neuronal cells $(26,27)$. In addition, MSC inhibits neuron apoptosis, improves neural cell differentiation, and promotes angiogenesis and CNS repair in MS patients (20). 


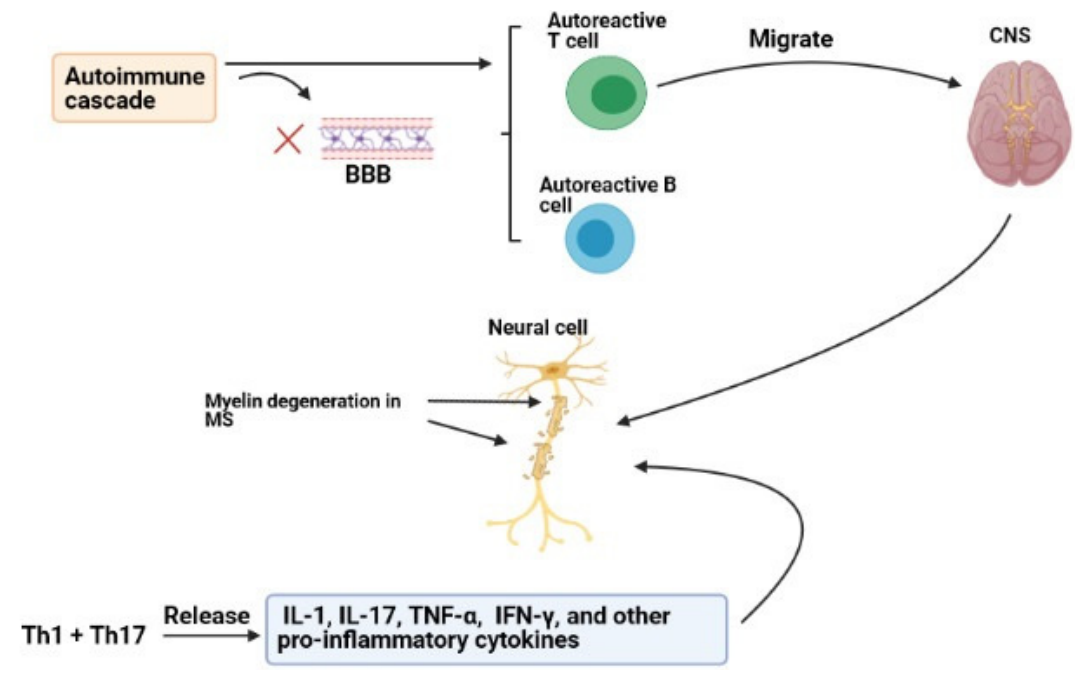

Fig. 1. The roles of immune responses in the pathogenesis of MS.

MSC regulates immune responses via suppressing the functions of B, T cells, and other immune cells (28). Studies have shown that intravascular injection of MSC induces $\mathrm{T}$ cell tolerance against myelin glycoproteins and improves CNS tissue repair (29). Intravenous injection of syngeneic MSC to animals with experimental autoimmune encephalomyelitis (EAE), as a model of MS, induces tolerance in MOG-specific T cells, which results in the reduction in immune cell infiltrations to the CNS and myelin destruction and improves the clinical course $(30,31)$. MSCs inhibit immune responses through the secretions of anti-inflammatory cytokines such as TGF- $\beta$, indoleamine-pyrrole 2, 3-dioxygenase (IDO), and prostaglandinE-2 (PGE-2) (32).

In vivo studies have indicated that MSCs are able to inhibit the activation and proliferation of Th1 cells and CD8+ $\mathrm{T}$ cell-mediated cytotoxicity functions through cell-cell interactions, which consequently lead to an impairment in the activation and proliferation of $\mathrm{B}$ cells and production of antibody (33). Moreover, MSC can enhance the activation of suppressor of cytokine signaling 3 (SOCS3) and control Th17 differentiation via IFN- $\gamma$ pathway (34). IDO production is another mechanism used by MSC for inhibiting immune responses (34). IDO depletes tryptophan from the environment of lymphocytes which has crucial role in lymphocyte activations (35). MSC induces peripheral dendritic cells (DCs) to secret IL-10 and thereby promotes the development of regulatory $\mathrm{T}$ cells (Treg) (35).

Recent studies suggest that MSCs improve peripheral tolerance through preventing the differentiation and function of DCs leading to reduction in antigen presentation and subsequently inhibition of clonal expansion of autor- eactive T cells (36). MSCs secrete hepatocyte growth factor (HGF) which increases tolerogenic DCs (37). It is reported that injection of MSC with HGF to EAE mice reduced CNS inflammation and immune cell infiltrations (37). Thus, it is likely that HGF derived from MSC is a good candidate for the treatment of MS. In several studies, genetically modified MSCs have been used to over express anti-inflammatory cytokines such as IL-10, and IL-4 (38). These studies have shown that MSCs suppress immune responses, reduce $\mathrm{BBB}$ injury, and improve remyelination of neurons in EAE mice (Fig. 2) (39).

\section{Human Bone Marrow-Derived MSCs (hBM-MSCs)}

The hBM-MSC, as a nonhematopoietic BM cell, includes approximately $0.0001 \sim 0.01 \%$ of all BM-nucleated cells (39). MSCs obtained from bone marrow have multiple properties including: I) differentiation into mesodermal lineage cells, II) stromal marker expressions, III) colony formations that contribute to haemopoiesis (40). Regarding therapeutic aspects of hBM-MSCs in neurological disorders, it is stated that these cells can promote functional recovery in relapsing-remitting and chronic types of MS mouse model probably through reducing demyelination regions and inflammatory infiltrates, enhancing brain-derived neurotrophic factor (BDNF) expression, and inducing oligodendrogenesis (41). Some studies have shown that BM-MSCs possess immunomodulatory effects in EAE mice (36). They can exert immunoregulatory impacts through releasing various bioactive agents which suppress the proliferation of $\mathrm{B}$ and $\mathrm{T}$ cells and the maturation of antigen-presenting cells (APCs) (42). These cells play neuroprotective roles via inducing local progenitor 


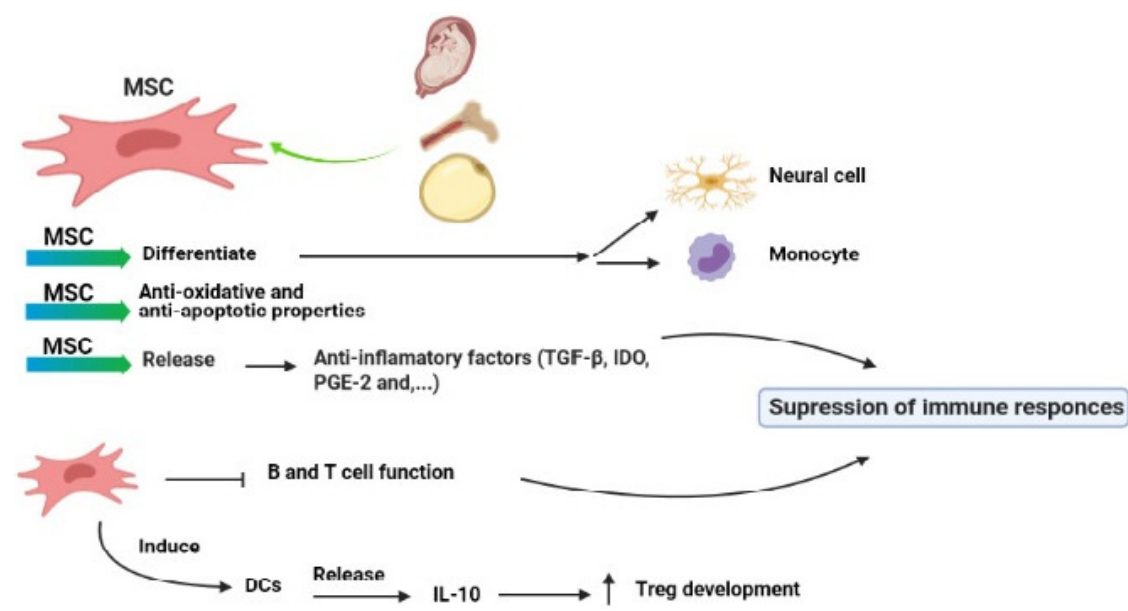

Fig. 2. Immunoregulatory impacts and therapeutic effects of MSCs.

cells and suppressing scar creation, gliosis, and neuron apoptosis (43). In addition to protective impacts, they are able to differentiate into the neurons and enhance the replacement of the cells (43). Nevertheless, the isolation of BM-MSCs is painful, invasive, and low efficiency (44). In EAE, BM-MSCs are efficient only when they are administrated before disease initiation, and have few curative effects in stabilized stage of disease (13). Thus, other sources of MSCs can be useful for MS treatment.

\section{Human Umbilical Cord (hUC)-MSCs}

Among several sources of MSCs, the utilization of human umbilical cord (hUC)-MSC has significant benefits such as less ethical issues, less invasive methods for its isolation, great proliferation potential, little immunogenicity capacity, and differentiation capacity into various lineages (45). Multiple studies have suggested hUC-MSC administration in autoimmune conditions like encephalomyelitis, type 1 diabetes, and rheumatoid arthritis due to its regulatory impacts on immune reactions (46-48). HUC-MSCs have significant effects on tissue recovery and immunoregulation (49). In comparison with BM-MSC, hUC-MSCs significantly have the decreased expression of HLA-I, increased expansion capacity, and more rapid growth in vitro (50). HUC-MSCs can also increase Treg number in vitro and in vivo (51). Liu et al. (48) showed that hUC-MSCs can improve behavioral activities and diminish the histopathological impairments of encephalomyelitis mouse models. They also declared that this mesenchymal source can dramatically elevate IL-4 and IL-10 and reduce IL-1 and IL-6 levels. In addition, hUC-MSCs can release several nerve growth factors, for example, BDNF, glial cell-derived neurotrophic factor (GDNF). Furthermore, hUC-MSCs can differentiate into oligoden- drocyte precursor cells and enhance axonal growth (52). In line with the immunomodulatory effects of these cells, it is demonstrated that hUC-MSCs cultured with peripheral blood mononuclear cells (PBMCs) from healthy individuals can promote Treg frequency and anti-inflammatory cytokine secretions (Fig. 3) (51, 53).

\section{Human Adipose-Derived MSCs (AD-MSCs)}

AD-MSC is a subset of MSCs isolated by collagenase digests of adipose tissue. Adipose tissue is available, abundant, easily accessible for use, and contain high levels of MSCs (about 100 1000 MSCs per gram of fat). Therefore, this tissue is considered as a valuable source of the cell for cellular therapy. AD-MSCs have the neurogenic, cardiogenic, myogenic, chondrogenic, osteogenic, and adipogenic capacity in vitro, which can be obtained and used to stem cell therapy by less invasive methods $(6,54)$. AD-MSCs can express $\alpha 4$ integrin, an adhesive molecule, and thereby have the ability to migrate in different organs (55). Previous studies have demonstrated that autologous and allogeneic AD-MSCs can be useful in the treatment of various diseases such as MS, diabetes, Parkinson's disease, autoimmune encephalomyelitis (56-59). In line with this notion, $\mathrm{Li}$ et al. revealed that intravenously injection of AD-MSC to EAE mice contributed to the reduction in infiltrations of inflammatory cells in the CNS and significantly inhibited demyelination and axonal loss $(8,59)$. These cells release various growth factors including anti-apoptotic, angiogenic and neurotrophic mediators which have significant roles in many cellular mechanisms such as cell differentiation, proliferation, and maturation (60). In contrast with BM-MSCs, AD-MSCs express integrin $\alpha$ $4 \beta 1$. Thus, it is thought that AD-MSC has more capabilities for stem cell-based cell therapy, due perhaps to its 


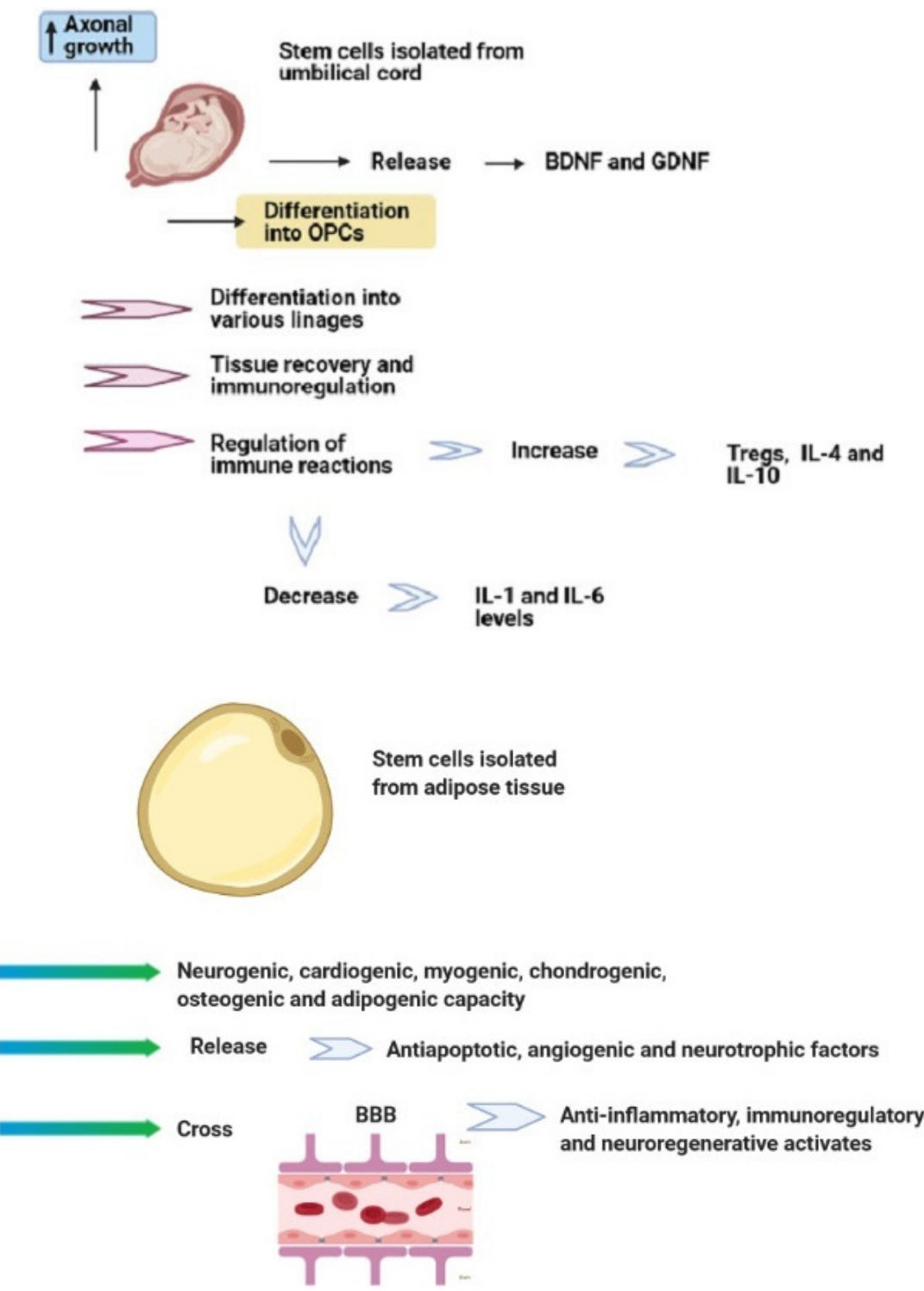

Fig. 3. Immunomodulatory effects and therapeutic features of hUC-MSCs.

Fig. 4. Immunoregulatory impacts and therapeutic features of AD-MSCs in degenerative diseases.

potential to pass the BBB and exert its effects such as anti-inflammatory, immunoregulatory, and neurodegenerative (Fig. 4) (5). Recently, several studies have been performed in this field $(61,62)$. Based on their results, the researchers are hopeful to find a standard method for treatment of MS by these cells (62). However, it seems that many concerns regarding the use of MSC such as tumorigenesis and immune-rejection after clinical application must be addressed in future works.

\section{Human Amniotic Epithelial Cells (hAECs)}

hAEC is a potential source of stem cell which can be easily isolated from the amniotic membrane (AM), the inner layer of the fetal membranes $(18,63-65)$. These cells can express some markers of pluripotent stem cells, such as Rex-1, FGF-T, SSEA-4, Sox-2, Nanog, and Oct4, which some of them play critical roles in self-renewal and pluripotency properties in induced pluripotent stem (iPS) cells and embryonic stem cells (ESCs) (66). hAEC displays multilineage differentiation potential and has the ability to differentiation into different cells such as the neural cells, pancreatic cells, hepatocytes, adipocytes, cardiomyocytes, and myocytes, which originate from the endoderm, mesoderm, and ectoderm (12). Extensive data from the literature have indicated that hAECs have immunoregulatory effects on adaptive and innate immune systems (14, $63,67)$. They have inhibitory impacts on the migrations of neutrophil and macrophage, proliferation of $\mathrm{B}$ cell, activations of natural killer $(\mathrm{NK})$ and $\mathrm{CD} 4+\mathrm{T}$ cells, and se- 
cretions of pro-inflammatory cytokines of CD4+ T cells $(12,18,68,69)$. The immunoregulatory features of hAEC are mainly mediated by secretions of immunoinhibitory agents, including interleukin-4 (IL-4), PG-E2, and transforming growth factor-beta (TGF- $\beta$ ) (70-73). Moreover, immunomodulatory impacts of hAECs may be mediated by the increase of Tregs and Th2 cells, IL-2, IL-5, and IL-10 levels, inhibition of pathogenic $\mathrm{T}$ cell reactions, and preservation of the peripheral naive $\mathrm{CD} 4+\mathrm{T}$ cell source $(74,75)$. Thus, hAECs may be acted as a useful cell source for MS treatment $(70,74)$. To support this notion, these cells have a significant impact on shift in the immune system away from Th1 immunity towards Th2 responses (74). It is reported that hAECs-treated EAE mice experienced significant reductions in demyelination and infiltration of $\mathrm{CD} 3+\mathrm{T}$ cell and F4/80 + monocyte/macrophage into the CNS (74). Some reports have indicated that hAECs inhibit the differentiation of Th17 cells through reducing the expressions of TGF- $\beta$ and IL-6, which have indispensible roles in Th17 cell differentiation (67). Other studies have indicated that hAECs are able to produce alpha-fetoprotein (AFP), which is involved in the reduction of lymphocyte function and neuroinflammation in MS animal model $(76,77)$. Moreover, they can reside in inflammation locations, such as the brain, and subsequently decrease grey and white matter damages (78). hAEC can release neurotrophic agents such as nerve growth factor (NGF), neurotrophin-3 (NT-3) and brain-derived neurotrophic factor (BDNF) (Fig. 5) (79, 80). These properties along with low antigenicity provide further confirmations to support therapeutic features of hAECs in managing and controlling in- flammatory neurological disorders such as MS (70). hAECs have a restricted proliferative potential due to lacking telomerase $(66,70,74,81)$, which may reduce potential tumorigenicity of stem cell-based therapies. Nevertheless, it is thought that additional studies and more information are required to clarify the possible ability of hAECs in treating diseases with immune pathophysiology.

\section{Comparison of hAECs with MSCs from Different Sources}

There are some similarities and differences between hAECs and MSCs derived from different sources including morphologic and tumorigenic properties, angiogenesis capacities, immunomodulatory features, and ethical issues related to their isolations and applications $(44,82)$. In terms of morphology, hAECs indicate a cobblestone-like morphology, and cultured hAMSCs have a spindle fibroblast-like morphology (83). The morphologic feature of BM-MSCs can be ranged from fibroblast-like spindleshaped cells to large flat cells in culture (84). MSCs from other sources, such as hUC-MSCs and AD-MSCs, show spindle shapes in the culture $(85,86)$. The collection of amniotic cells can easily be performed by prenatal testing. Moreover, the amniotic membrane can be collected using standard isolation techniques after cesarean section which are noninvasive without detrimental effects on human embryos and ethical issues (82). However, some ethical problems are proposed to clinical applications of MSCs and the isolation of some MSC sources $(84,87)$. As mentioned previous, the isolation of hBM-MSCs is invasive, painful,

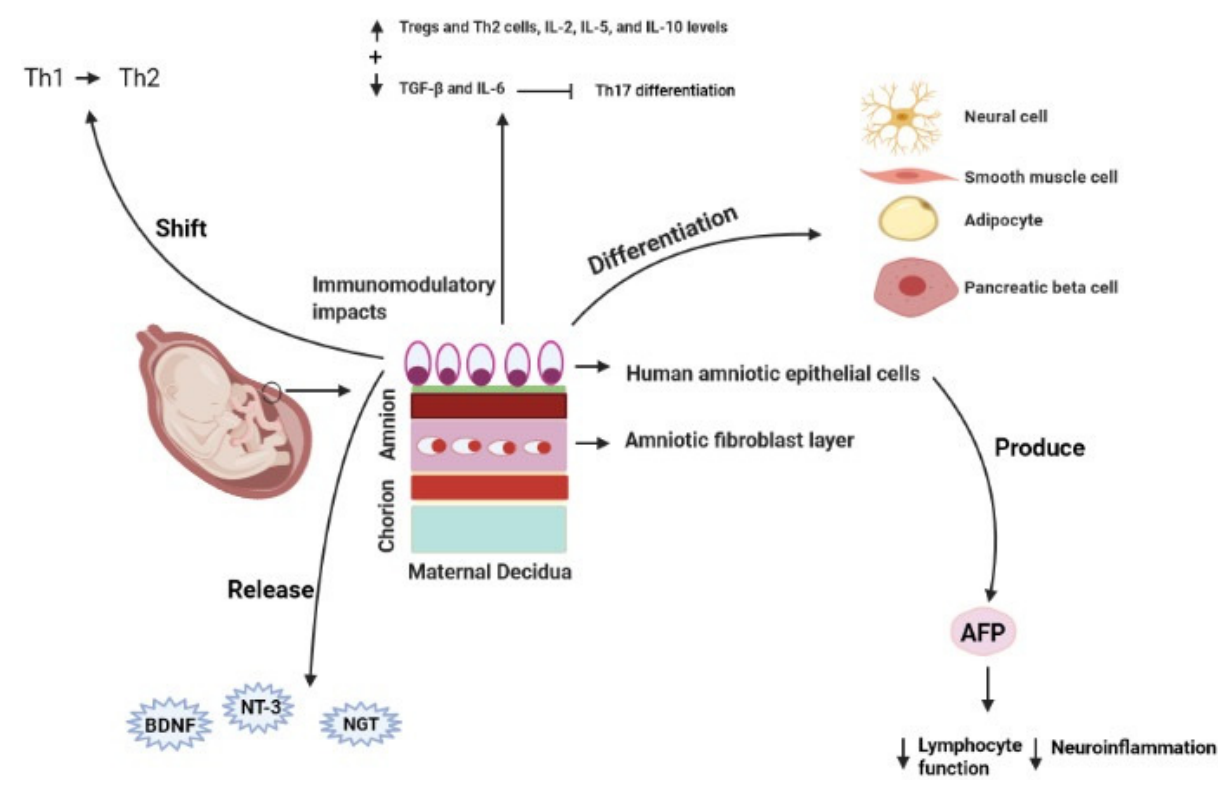

Fig. 5. Immunomodulatory effects and stem cell characteristics of hAECs. 
and low efficiency (44). HAECs don't have tumorigenic capacity, and there is no document about the tumorigenicity of amnion membrane or membrane-originated cells when they are used to clinical applications (14). However, it is reported that MSCs may elevate tumor growth in some cancer mouse models (88). HAECs, BMMSCs, and AD-MSCs can promote angiogenesis through releasing angiogenic factors such as VEGF, HGF, EGF and some mechanisms associated to protease and cytokine productions $(83,89)$. Based on evidence, hAECs have better immunoregulatory effects but lesser osteogenic impacts than MSCs derived from BM and human amniotic fluid (hAF) (90). These cells, similar to MSCs, express some MSC markers such as CD44, CD90, and CD105. However, hAECs possess higher levels of SSEA4 and SSEA3 expressions than hBM-MSCs and hAFMSC, indicating more multipotent potential of hAECs (14, 91). Furthermore, hAECs and hAFMSC express higher PD-L1 and PD-L2 levels than hBM-MSCs, thereby these cells may have more effective effects in peripheral tolerance in different cells of the immune system $(90,92)$.

\section{Mesenchymal Stem Cell-Based Cell Therapy and Clinical Trials}

Recently, several clinical trials were preformed using MSCs as a treatment for MS. In a phase II clinical trial, nine relapsing-remitting multiple sclerosis (RRMS) patients were treated with MSCs for six months resulting in the reduction of lesions in magnetic resonance imaging (MRI) (43). In 2010, Yamout et al. (43) injected autologous BM-MSCs to nine secondary progressive multiple sclerosis (SPMS) and one RRMS patients. After three months to one year, they observed improved clinical features in MS patients. In this phase IIa clinical trial, 10 SPMS patients received intravascular MSCs for six months and the researchers observed remyelination and neuroprotection effect of MSCs (43). Moreover, in another study conducted by Mohyeddin Bonab et al. (93) in 2007, MSC was intrathecally injected to $10 \mathrm{MS}$ patients and investigated disease procession. The disease development was gradually decreased in half of patients upon MSC application. In a study on 22 patients with primary progressive multiple sclerosis (PPMS), it was reported that intravenously and intrathecally injections of BM-MSCs had helpful effects in MS treatment (32). In a triple-blind and placebo-controlled investigation on 30 patients with SPMS, it was shown that AD-MSCs infusion is a feasible and safe procedure in SPMS patients (94). In another study by Staff et al. (95) the safety of intrathecal admin- istration of AD-MSCs in amyotrophic lateral sclerosis (ALS) cases was reported. Li et al. (96) assessed the therapeutic influences of another MSC source. They demonstrated that hUC-MSCs transplantation decreased MS symptoms and relapse occurrence compared to control subjects. Furthermore, they revealed a shift from Th1 to Th2 immunity in the hUC-MSCs-administrated group. In addition, in another study, Riordan et al. (97) indicated the safety of hUC-MSCs transplantation and useful impacts of these cells on life quality and brain lesion in MS cases.

\section{Conclusions}

Stem cell-based cell therapy is getting to be a treatment for MS and other neurological diseases. However, there is an inconsistency in the results of previous studies. This discrepancy proposes that more studies are needed to demonstrate the exact role of stem cells in MS treatment. Among several types of stem cells, MSCs are more likely to find a place in future treatments for MS because these cells have different mechanisms to regulate immune responses and repair CNS damages. Furthermore, MSCs have a supportive role on axon and the neural stability and have anti-oxidant, anti-apoptotic and trophic factors secretion properties. A growing body of evidence recommends that umbilical cord and adipose tissue can be more effective for stem cell therapy on the basis of MSCs. Moreover, hAECs are considered as a novel stem cell source that can have a potential for differentiation into derivates of three germinal layers such as neural cells and possess immunoregulatory effects. Therefore, they can also have the ability to MS treatment. However, more experimental investigations should be performed to explain their effectiveness and mechanisms in the treatment of this disease.

\section{Acknowledgments}

This study was no financially supported and was performed by personal capacity.

\section{Potential Conflict of Interest}

The authors have no conflicting financial interest.

\section{References}

1. Martin JB. Molecular basis of the neurodegenerative disorders. N Engl J Med 1999;340:1970-1980

2. Jafarzadeh Bejargafshe $M$, Hedayati $M$, Zahabiasli S, Tahmasbpour E, Rahmanzadeh S, Nejad-Moghaddam A. 
Safety and efficacy of stem cell therapy for treatment of neural damage in patients with multiple sclerosis. Stem Cell Investig 2019;6:44

3. Minzenberg MJ. Dousing the flames to repair brains. Sci Transl Med 2010;2:27ec60

4. Yousefi F, Lavi Arab F, Saeidi K, Amiri H, Mahmoudi M. Various strategies to improve efficacy of stem cell transplantation in multiple sclerosis: focus on mesenchymal stem cells and neuroprotection. J Neuroimmunol 2019;328: 20-34

5. Ghasemi N. Therapeutic effects of adipose derived mesenchymal stem cells on remyelination process in inflammatory demyelinating diseases. J Histol Histopathol 2015;2:8

6. Abdallah AN, Shamaa AA, El-Tookhy OS. Evaluation of treatment of experimentally induced canine model of multiple sclerosis using laser activated non-expanded adipose derived stem cells. Res Vet Sci 2019;125:71-81

7. Nguyen H, Zarriello S, Coats A, Nelson C, Kingsbury C, Gorsky A, Rajani M, Neal EG, Borlongan CV. Stem cell therapy for neurological disorders: a focus on aging. Neurobiol Dis 2019;126:85-104

8. Namchaiw P, Wen H, Mayrhofer F, Chechneva O, Biswas $\mathrm{S}$, Deng W. Temporal and partial inhibition of GLI1 in neural stem cells (NSCs) results in the early maturation of NSC derived oligodendrocytes in vitro. Stem Cell Res Ther 2019;10:272

9. Genc B, Bozan HR, Genc S, Genc K. Stem cell therapy for multiple sclerosis. Adv Exp Med Biol 2019;1084:145-174

10. Bitsch A, Bruhn H, Vougioukas V, Stringaris A, Lassmann $\mathrm{H}$, Frahm J, Brück W. Inflammatory CNS demyelination: histopathologic correlation with in vivo quantitative proton MR spectroscopy. AJNR Am J Neuroradiol 1999;20:16191627

11. Akle CA, Adinolfi M, Welsh KI, Leibowitz S, McColl I. Immunogenicity of human amniotic epithelial cells after transplantation into volunteers. Lancet 1981;2:1003-1005

12. Motedayyen H, Zarnani AH, Tajik N, Ghotloo S, Rezaei A. Immunomodulatory effects of human amniotic epithelial cells on naive $\mathrm{CD}^{+}{ }^{+} \mathrm{T}$ cells from women with unexplained recurrent spontaneous abortion. Placenta 2018;71:31-40

13. Darlington PJ, Boivin MN, Bar-Or A. Harnessing the therapeutic potential of mesenchymal stem cells in multiple sclerosis. Expert Rev Neurother 2011;11:1295-1303

14. Miki T, Lehmann T, Cai H, Stolz DB, Strom SC. Stem cell characteristics of amniotic epithelial cells. Stem Cells 2005; 23:1549-1559

15. Rahmati M, Ghannadian SM, Kasiri N, Ahmadi L, Motedayyen H, Shaygannejad V, Pourazar A, Alsahebfosoul F, Ganjalikhani Hakemi M, Eskandari N. Modulation of Th17 proliferation and IL-17A gene expression by acetylated form of Apigenin in patients with multiple sclerosis. Immunol Invest 2021;50:216-229

16. Sedaghat N, Motedayyen H, Alsahebfosoul F, Etemadifar M, Ostadi V, Kianpour F, Zarkesh Esfahani SH. Increased expression of lymphocyte activation gene- 3 by regulatory $\mathrm{t}$ cells in multiple sclerosis patients with fingolimod treatment Turkish J Immunol 2019;7:31-39

17. Imitola J. Regenerative neuroimmunology: the impact of immune and neural stem cell interactions for translation in neurodegeneration and repair. J Neuroimmunol 2019; 331:1-3

18. Motedayyen H, Rezaei A, Zarnani AH, Tajik N. Human amniotic epithelial cells inhibit activation and pro-inflammatory cytokines production of naive CD4 $+\mathrm{T}$ cells from women with unexplained recurrent spontaneous abortion. Reprod Biol 2018;18:182-188

19. Sedaghat N, Motedayyen H, Etemadifar M, Zarkesh H, Kianpour F, Vestri E, Alsahebfosoul F. Effect of fingolimod on the frequency of regulatory $\mathrm{T}$ cells in patients with relapsing-remitting multiple sclerosis. J Immun Res 2018;5: 1032

20. Pirttilä T, Nurmikko T. CSF oligoclonal bands, MRI, and the diagnosis of multiple sclerosis. Acta Neurol Scand 1995; 92:468-471

21. Markarian CF, Frey GZ, Silveira MD, Chem EM, Milani AR, Ely PB, Horn AP, Nardi NB, Camassola M. Isolation of adipose-derived stem cells: a comparison among different methods. Biotechnol Lett 2014;36:693-702

22. Fukuchi Y, Nakajima H, Sugiyama D, Hirose I, Kitamura T, Tsuji K. Human placenta-derived cells have mesenchymal stem/progenitor cell potential. Stem Cells 2004;22: 649-658

23. Schwab KE, Hutchinson P, Gargett CE. Identification of surface markers for prospective isolation of human endometrial stromal colony-forming cells. Hum Reprod 2008;23: 934-943

24. Xu C, Diao YF, Wang J, Liang J, Xu HH, Zhao ML, Zheng B, Luan Z, Wang JJ, Yang XP, Wei MG, Duan JH, Wang KQ, Chen C, Chen F, Ming D, Zhang S, Sun HT, Li XH. Intravenously infusing the secretome of adipose-derived mesenchymal stem cells ameliorates neuroinflammation and neurological functioning after traumatic brain injury. Stem Cells Dev 2020;29:222-234

25. Song CG, Zhang YZ, Wu HN, Cao XL, Guo CJ, Li YQ, Zheng MH, Han H. Stem cells: a promising candidate to treat neurological disorders. Neural Regen Res 2018;13: 1294-1304

26. Samper Agrelo I, Schira-Heinen J, Beyer F, Groh J, Bütermann C, Estrada V, Poschmann G, Bribian A, Jadasz JJ, Lopez-Mascaraque L, Kremer D, Martini R, Müller HW, Hartung HP, Adjaye J, Stühler K, Küry P. Secretome analysis of mesenchymal stem cell factors fostering oligodendroglial differentiation of neural stem cells in vivo. Int J Mol Sci 2020;21:4350

27. Jaramillo-Merchán J, Jones J, Ivorra JL, Pastor D, Viso-León MC, Armengól JA, Moltó MD, Geijo-Barrientos E, Martínez S. Mesenchymal stromal-cell transplants induce oligodendrocyte progenitor migration and remyelination in a chronic demyelination model. Cell Death Dis 2013;4:e779

28. Forte A, Finicelli M, Mattia M, Berrino L, Rossi F, De Feo 
M, Cotrufo M, Cipollaro M, Cascino A, Galderisi U. Mesenchymal stem cells effectively reduce surgically induced stenosis in rat carotids. J Cell Physiol 2008;217:789799

29. Peng Z, Gao W, Yue B, Jiang J, Gu Y, Dai J, Chen L, Shi Q. Promotion of neurological recovery in rat spinal cord injury by mesenchymal stem cells loaded on nerve-guided collagen scaffold through increasing alternatively activated macrophage polarization. J Tissue Eng Regen Med 2018;12: e1725-e1736

30. Brück W, Porada P, Poser S, Rieckmann P, Hanefeld F, Kretzschmar HA, Lassmann H. Monocyte/macrophage differentiation in early multiple sclerosis lesions. Ann Neurol 1995;38:788-796

31. Freedman MS, Bar-Or A, Atkins HL, Karussis D, Frassoni F, Lazarus H, Scolding N, Slavin S, Le Blanc K, Uccelli A. The therapeutic potential of mesenchymal stem cell transplantation as a treatment for multiple sclerosis: consensus report of the International MSCT Study Group. Mult Scler 2010;16:503-510

32. Squillaro T, Peluso G, Galderisi U. Clinical trials with mesenchymal stem cells: an update. Cell Transplant 2016;25: 829-848

33. Najar M, Fayyad-Kazan M, Meuleman N, Bron D, FayyadKazan H, Lagneaux L. Mesenchymal stromal cells of the bone marrow and natural killer cells: cell interactions and cross modulation. J Cell Commun Signal 2018;12:673-688

34. Liu X, Ren S, Qu X, Ge C, Cheng K, Zhao RC. Mesenchymal stem cells inhibit Th17 cells differentiation via IFN- $\gamma$-mediated SOCS3 activation. Immunol Res 2015; 61:219-229

35. Wang D, Huang S, Yuan X, Liang J, Xu R, Yao G, Feng $\mathrm{X}$, Sun L. The regulation of the Treg/Th17 balance by mesenchymal stem cells in human systemic lupus erythematosus. Cell Mol Immunol 2017;14:423-431

36. Selmani Z, Naji A, Gaiffe E, Obert L, Tiberghien P, Rouas-Freiss N, Carosella ED, Deschaseaux F. HLA-G is a crucial immunosuppressive molecule secreted by adult human mesenchymal stem cells. Transplantation 2009;87(9 Suppl):S62-S66

37. Lu Z, Chang W, Meng S, Xu X, Xie J, Guo F, Yang Y, Qiu H, Liu L. Mesenchymal stem cells induce dendritic cell immune tolerance via paracrine hepatocyte growth factor to alleviate acute lung injury. Stem Cell Res Ther 2019;10:372

38. Razmkhah M, Jaberipour M, Erfani N, Habibagahi $M$, Talei AR, Ghaderi A. Adipose derived stem cells (ASCs) isolated from breast cancer tissue express IL-4, IL-10 and TGF- $\beta 1$ and upregulate expression of regulatory molecules on $\mathrm{T}$ cells: do they protect breast cancer cells from the immune response? Cell Immunol 2011;266:116-122

39. Duffy MM, Ritter T, Ceredig R, Griffin MD. Mesenchymal stem cell effects on T-cell effector pathways. Stem Cell Res Ther 2011;2:34

40. Uccelli A, Laroni A, Freedman MS. Mesenchymal stem cells for the treatment of multiple sclerosis and other neu- rological diseases. Lancet Neurol 2011;10:649-656

41. Ryu CH, Park KY, Hou Y, Jeong CH, Kim SM, Jeun SS. Gene therapy of multiple sclerosis using interferon $\beta$-secreting human bone marrow mesenchymal stem cells. Biomed Res Int 2013;2013:696738

42. Patel SA, Sherman L, Munoz J, Rameshwar P. Immunological properties of mesenchymal stem cells and clinical implications. Arch Immunol Ther Exp (Warsz) 2008;56:1-8

43. Yamout B, Hourani R, Salti H, Barada W, El-Haji T, Al-Kutoubi A, Herlopian A, Baz EK, Mahfouz R, Khalil-Hamdan R, Kreidieh NM, El-Sabban M, Bazarbachi A. Bone marrow mesenchymal stem cell transplantation in patients with multiple sclerosis: a pilot study. J Neuroimmunol 2010;227:185-189

44. Quirici N, Soligo D, Bossolasco P, Servida F, Lumini C, Deliliers GL. Isolation of bone marrow mesenchymal stem cells by anti-nerve growth factor receptor antibodies. Exp Hematol 2002;30:783-791

45. Ding Y, Yang H, Feng JB, Qiu Y, Li DS, Zeng Y. Human umbilical cord-derived MSC culture: the replacement of animal sera with human cord blood plasma. In Vitro Cell Dev Biol Anim 2013;49:771-777

46. Hu J, Yu X, Wang Z, Wang F, Wang L, Gao H, Chen Y, Zhao W, Jia Z, Yan S, Wang Y. Long term effects of the implantation of Wharton's jelly-derived mesenchymal stem cells from the umbilical cord for newly-onset type 1 diabetes mellitus. Endocr J 2013;60:347-357

47. Li JF, Yin HL, Shuboy A, Duan HF, Lou JY, Li J, Wang HW, Wang YL. Differentiation of hUC-MSC into dopaminergic-like cells after transduction with hepatocyte growth factor. Mol Cell Biochem 2013;381:183-190

48. Liu R, Zhang Z, Lu Z, Borlongan C, Pan J, Chen J, Qian L, Liu Z, Zhu L, Zhang J, Xu Y. Human umbilical cord stem cells ameliorate experimental autoimmune encephalomyelitis by regulating immunoinflammation and remyelination. Stem Cells Dev 2013;22:1053-1062

49. Rong LJ, Chi Y, Yang SG, Chen DD, Chen F, Xu SX, Zhang DL, Ma FX, Lu SH, Han ZC. [Effects of interferon$\gamma$ on biological characteristics and immunomodulatory property of human umbilical cord-derived mesenchymal stem cells]. Zhongguo Shi Yan Xue Ye Xue Za Zhi 2012; 20:421-426. Chinese

50. Lu Z, Zhao H, Xu J, Zhang Z, Zhang X, Zhang Y, Liu $\mathrm{Z}, \mathrm{Xu}$ Y. Human umbilical cord mesenchymal stem cells in the treatment of secondary progressive multiple sclerosis. J Stem Cell Res Ther 2013;S6:2

51. Yang H, Yang H, Xie Z, Wei L, Bi J. Systemic transplantation of human umbilical cord derived mesenchymal stem cells-educated $\mathrm{T}$ regulatory cells improved the impaired cognition in A $\beta$ PPswe/PS1dE9 transgenic mice. PLoS One 2013;8:e69129

52. Dong H, Li G, Shang C, Yin H, Luo Y, Meng H, Li X, Wang Y, Lin L, Zhao M. Umbilical cord mesenchymal stem cell (UC-MSC) transplantations for cerebral palsy. Am J Transl Res 2018;10:901-906

53. Yang H, Sun J, Wang F, Li Y, Bi J, Qu T. Umbilical 
cord-derived mesenchymal stem cells reversed the suppressive deficiency of $\mathrm{T}$ regulatory cells from peripheral blood of patients with multiple sclerosis in a co-culture- a preliminary study. Oncotarget 2016;7:72537-72545

54. Mazini L, Rochette L, Amine M, Malka G. Regenerative capacity of adipose derived stem cells (ADSCs), comparison with mesenchymal stem cells (MSCs). Int J Mol Sci 2019;20:2523

55. Ragerdi Kashani I, Hedayatpour A, Pasbakhsh P, Kafami L, Atlasi N, Pirhajati Mahabadi V, Mamoudi R, Baazm M. $17 \beta$-estradiol enhances the efficacy of adipose-derived mesenchymal stem cells on remyelination in mouse model of multiple sclerosis. Acta Med Iran 2012;50:789-797

56. Stepien A, Dabrowska NL, Maciagowska M, Macoch RP, Zolocinska A, Mazur S, Siennicka K, Frankowska E, Kidzinski R, Chalimoniuk M, Pojda Z. Clinical application of autologous adipose stem cells in patients with multiple sclerosis: preliminary results. Mediators Inflamm 2016; 2016:5302120

57. Gadelkarim M, Abushouk AI, Ghanem E, Hamaad AM, Saad AM, Abdel-Daim MM. Adipose-derived stem cells: effectiveness and advances in delivery in diabetic wound healing. Biomed Pharmacother 2018;107:625-633

58. Chi K, Fu RH, Huang YC, Chen SY, Hsu CJ, Lin SZ, Tu CT, Chang LH, Wu PA, Liu SP. Adipose-derived stem cells stimulated with n-butylidenephthalide exhibit therapeutic effects in a mouse model of Parkinson's disease. Cell Transplant 2018;27:456-470

59. Li J, Chen Y, Chen Z, Huang Y, Yang D, Su Z, Weng Y, Li X, Zhang X. Therapeutic effects of human adipose tissue-derived stem cell (hADSC) transplantation on experimental autoimmune encephalomyelitis (EAE) mice. Sci Rep 2017;7:42695

60. Dai R, Wang Z, Samanipour R, Koo KI, Kim K. Adiposederived stem cells for tissue engineering and regenerative medicine applications. Stem Cells Int 2016;2016:6737345

61. Ghasemi N, Razavi S, Mardani M, Esfandiari E, Salehi H, Zarkesh Esfahani SH. Transplantation of human adipose-derived stem cells enhances remyelination in lysolecithin-induced focal demyelination of rat spinal cord. Mol Biotechnol 2014;56:470-478

62. Tomita K, Madura T, Mantovani C, Terenghi G. Differentiated adipose-derived stem cells promote myelination and enhance functional recovery in a rat model of chronic denervation. J Neurosci Res 2012;90:1392-1402

63. Li H, Niederkorn JY, Neelam S, Mayhew E, Word RA, McCulley JP, Alizadeh H. Immunosuppressive factors secreted by human amniotic epithelial cells. Invest Ophthalmol Vis Sci 2005;46:900-907

64. Insausti CL, Blanquer M, García-Hernández AM, Castellanos G, Moraleda JM. Amniotic membrane-derived stem cells: immunomodulatory properties and potential clinical application. Stem Cells Cloning 2014;7:53-63

65. Fathi F, Atapour A, Eskandari N, Keyhanmehr N, Hafezi H, Mohammadi S, Motedayyen H. Regulatory T-cells and their impacts on cytokine profile of end-stage renal disease patients suffering from systemic lupus erythematosus. Int J Immunopathol Pharmacol 2019;33:2058738419863238

66. Yang PJ, Yuan WX, Liu J, Li JY, Tan B, Qiu C, Zhu XL, Qiu C, Lai DM, Guo LH, Yu LY. Biological characterization of human amniotic epithelial cells in a serum-free system and their safety evaluation. Acta Pharmacol Sin 2018;39:1305-1316

67. McDonald CA, Short M, Jenkin G, Bernard CCA. The potential of human amnion epithelial cells as an immunomodulatory and neuroregenerative treatment for multiple sclerosis. In: Atala A, Murphy S, editor. Perinatal Stem Cells. New York: Springer; 2014. 231-242

68. Alipour R, Motedayyen H, Sereshki N, Rafiee M, Alsahebfosul F, Pourazar A. Human amniotic epithelial cells affect the functions of neutrophils. Int J Stem Cells 2020;13:212-220

69. Khadem F, Esmaeil N, Rezaei A, Motadayen H, Khani B. Immunoregulatory effects of human amnion epithelial cells on natural killer and $\mathrm{T}$ cells in women with Recurrent Spontaneous Abortion (RSA). Turk J Immunol 2019;7:21-30

70. McDonald CA, Payne NL, Sun G, Moussa L, Siatskas C, Lim R, Wallace EM, Jenkin G, Bernard CC. Immunosuppressive potential of human amnion epithelial cells in the treatment of experimental autoimmune encephalomyelitis. J Neuroinflammation 2015;12:112

71. Motedayyen H, Esmaeil N, Tajik N, Khadem F, Ghotloo S, Khani B, Rezaei A. Method and key points for isolation of human amniotic epithelial cells with high yield, viability and purity. BMC Res Notes 2017;10:552

72. Taheri RA, Motedayyen H, Ghotloo S, Masjedi M, Mosaffa N, Mirshafiey A, Saffari M. The effect of lipopolysaccharide on the expression level of immunomodulatory and immunostimulatory factors of human amniotic epithelial cells. BMC Res Notes 2018;11:343

73. Motedayyen H, Fathi F, Fasihi-Ramandi M, Ali Taheri R. The effect of lipopolysaccharide on anti-inflammatory and pro-inflammatory cytokines production of human amniotic epithelial cells. Reprod Biol 2018;18:404-409

74. Liu YH, Vaghjiani V, Tee JY, To K, Cui P, Oh DY, Manuelpillai U, Toh BH, Chan J. Amniotic epithelial cells from the human placenta potently suppress a mouse model of multiple sclerosis. PLoS One 2012;7:e35758

75. Xu H, Zhang J, Tsang KS, Yang H, Gao WQ. Therapeutic potential of human amniotic epithelial cells on injuries and disorders in the central nervous system. Stem Cells Int 2019;2019:5432301

76. Han K, Lee JE, Kwon SJ, Park SY, Shim SH, Kim H, Moon JH, Suh CS, Lim HJ. Human amnion-derived mesenchymal stem cells are a potential source for uterine stem cell therapy. Cell Prolif 2008;41:709-725

77. Irony-Tur-Sinai $M$, Grigoriadis N, Tsiantoulas D, Touloumi $\mathrm{O}$, Abramsky O, Brenner T. Immunomodulation of EAE by alpha-fetoprotein involves elevation of immune cell apoptosis markers and the transcription factor FoxP3. J Neurol Sci 2009;279:80-87

78. Yawno T, Schuilwerve J, Moss TJ, Vosdoganes P, Westover 
AJ, Afandi E, Jenkin G, Wallace EM, Miller SL. Human amnion epithelial cells reduce fetal brain injury in response to intrauterine inflammation. Dev Neurosci 2013;35: 272-282

79. Meng XT, Chen D, Dong ZY, Liu JM. Enhanced neural differentiation of neural stem cells and neurite growth by amniotic epithelial cell co-culture. Cell Biol Int 2007;31: 691-698

80. Uchida S, Suzuki Y, Araie M, Kashiwagi K, Otori Y, Sakuragawa N. Factors secreted by human amniotic epithelial cells promote the survival of rat retinal ganglion cells. Neurosci Lett 2003;341:1-4

81. Uchida S, Inanaga Y, Kobayashi M, Hurukawa S, Araie M, Sakuragawa N. Neurotrophic function of conditioned medium from human amniotic epithelial cells. J Neurosci Res 2000;62:585-590

82. Kim EY, Lee KB, Kim MK. The potential of mesenchymal stem cells derived from amniotic membrane and amniotic fluid for neuronal regenerative therapy. BMB Rep 2014;47: $135-140$

83. Wu Q, Fang T, Lang H, Chen M, Shi P, Pang X, Qi G. Comparison of the proliferation, migration and angiogenic properties of human amniotic epithelial and mesenchymal stem cells and their effects on endothelial cells. Int J Mol Med 2017;39:918-926

84. Motamedi B, Ibrahim TAT, Abdul AB, Allaudin ZN, Moshrefi M, Hajghani $M$, Nematollahi-Mahani SN. Characteristics of human amniotic epithelial cells and bone marrow mesenchymal stem cells in a parallel study: hanging drop colony formation and doubling time. J Regen Med 2015;4:1

85. Wu KC, Chang YH, Liu HW, Ding DC. Transplanting human umbilical cord mesenchymal stem cells and hyaluronate hydrogel repairs cartilage of osteoarthritis in the minipig model. Ci Ji Yi Xue Za Zhi 2019;31:11-19

86. Debnath T, Chelluri LK. Standardization and quality assessment for clinical grade mesenchymal stem cells from human adipose tissue. Hematol Transfus Cell Ther 2019; 41:7-16

87. Serras ASM, Cipriano MZdRF, da Graça Silva PM, Miranda JPG. Challenges for deriving hepatocyte-like cells from umbilical cord mesenchymal stem cells for in vitro toxicology applications. In: Kitala D, Maurício AC, editor. Novel Perspectives of Stem Cell Manufacturing and Therapies. London: IntechOpen; 2021. 1-28

88. Xu Z, Wei W, Gagneur J, Perocchi F, Clauder-Münster S, Camblong J, Guffanti E, Stutz F, Huber W, Steinmetz LM. Bidirectional promoters generate pervasive transcription in yeast. Nature 2009;457:1033-1037

89. Kachgal S, Putnam AJ. Mesenchymal stem cells from adi- pose and bone marrow promote angiogenesis via distinct cytokine and protease expression mechanisms. Angiogenesis 2011;14:47-59

90. Si J, Dai J, Zhang J, Liu S, Gu J, Shi J, Shen SG, Guo L. Comparative investigation of human amniotic epithelial cells and mesenchymal stem cells for application in bone tissue engineering. Stem Cells Int 2015;2015:565732

91. Parolini O, Alviano F, Bagnara GP, Bilic G, Bühring HJ, Evangelista M, Hennerbichler S, Liu B, Magatti M, Mao $\mathrm{N}$, Miki T, Marongiu F, Nakajima $H$, Nikaido $T$, Portmann-Lanz CB, Sankar V, Soncini M, Stadler G, Surbek D, Takahashi TA, Redl H, Sakuragawa N, Wolbank S, Zeisberger S, Zisch A, Strom SC. Concise review: isolation and characterization of cells from human term placenta: outcome of the first international Workshop on Placenta Derived Stem Cells. Stem Cells 2008;26:300-311

92. Banas RA, Trumpower C, Bentlejewski C, Marshall V, Sing G, Zeevi A. Immunogenicity and immunomodulatory effects of amnion-derived multipotent progenitor cells. Hum Immunol 2008;69:321-328

93. Mohyeddin Bonab $M$, Yazdanbakhsh S, Lotfi J, Alimoghaddom K, Talebian F, Hooshmand F, Ghavamzadeh A, Nikbin B. Does mesenchymal stem cell therapy help multiple sclerosis patients? Report of a pilot study. Iran J Immunol 2007;4:50-57

94. Fernández O, Izquierdo G, Fernández V, Leyva L, Reyes V, Guerrero M, León A, Arnaiz C, Navarro G, Páramo MD, Cuesta A, Soria B, Hmadcha A, Pozo D, FernandezMontesinos R, Leal M, Ochotorena I, Gálvez P, Geniz MA, Barón FJ, Mata R, Medina C, Caparrós-Escudero C, Cardesa A, Cuende N. Adipose-derived mesenchymal stem cells (AdMSC) for the treatment of secondary-progressive multiple sclerosis: a triple blinded, placebo controlled, randomized phase I/II safety and feasibility study. PLoS One 2018;13:e0195891

95. Staff NP, Madigan NN, Morris J, Jentoft M, Sorenson EJ, Butler G, Gastineau D, Dietz A, Windebank AJ. Safety of intrathecal autologous adipose-derived mesenchymal stromal cells in patients with ALS. Neurology 2016;87:22302234

96. Li JF, Zhang DJ, Geng T, Chen L, Huang H, Yin HL, Zhang YZ, Lou JY, Cao B, Wang YL. The potential of human umbilical cord-derived mesenchymal stem cells as a novel cellular therapy for multiple sclerosis. Cell Transplant 2014;23 Suppl 1:S113-S122

97. Riordan NH, Morales I, Fernández G, Allen N, Fearnot NE, Leckrone ME, Markovich DJ, Mansfield D, Avila D, Patel AN, Kesari S, Paz Rodriguez J. Clinical feasibility of umbilical cord tissue-derived mesenchymal stem cells in the treatment of multiple sclerosis. J Transl Med 2018;16:57 